\title{
THE INFLUENCE OF REFERENCE GROUP AND PERCEIVED QUALITY TOWARD PURCHASE DECISION OF DECORATIVE COSMETICS FOR LIPS WITHOUT THE HALAL LABEL
}

\author{
Sausan Fauziya \\ fauziyasusan@gmail.com \\ Anggota HIMPSI Provinsi Banten
}

\author{
Ikhwan Lutfi \\ Ikhwan.lutfi@uinjkt.ac.id \\ Fakultas Psikologi UIN Syarif \\ Hidayatullah Jakarta
}

\begin{abstract}
The purpose of this research is to find out the influence of reference group and perceived quality toward purchase decisions of decorative cosmetics for lips without the halal label. The sample amount of 255 female students at Faculty of Psychology UIN Jakarta which were taken with non probability sampling. Data analysis used binary logistic regression analysis technique. The result found that there was significant effect of reference group and perceived quality on purchase decision which was explained in all independent variables was 30,8\%, while 69,2\% was influenced by external variable of this research. Overall these result indicated that the best predictor of purchase decision of decorative cosmetics for lips without halal label are performance, beauty bloggers, and serviceability. Therefore, for further research is suggested to examine another variables other namely culture, family, age, job, life style, personality, motivation and attitude is recommended for future research.
\end{abstract}

Keywords: purchase decision, reference group, perceived quality

\begin{abstract}
Abstrak
Penelitian ini bertujuan untuk mengetahui pengaruh kelompok referensi dan persepsi kualitas produk terhadap keputusan membeli kosmetik dekoratif bibir tanpa label halal. Sampel berjumlah 255 mahasiswi Fakultas Psikologi UIN Jakarta yang diambil dengan non probability sampling. Analisis data menggunakan teknik analisis regresi logistik binary. Hasil penelitian ini menunjukkan bahwa terdapat pengaruh yang signifikan kelompok referensi dan persepsi kualitas produk terhadap keputusan membeli kosmetik dekoratif bibir tanpa label halal. Besarnya pengaruh seluruh variabel independen terhadap keputusan membeli adalah sebesar 30,8\%, sedangkan 69,2\% lainnya dipengaruhi oleh variabel lain di luar penelitian ini. Sementara hasil analisis proporsi varians masingmasing variabel secara terpisah, ditemukan sumbangan yang paling besar terhadap keputusan membeli adalah persepsi kualitas dimensi performance, kelompok referensi beauty blogger, dan persepsi kualitas dimensi serviceability. Penelitian selanjutnya diharapkan dapat mengembangkan penelitian ini dengan melibatkan variabel lain, seperti kebudayaan, keluarga, usia, pekerjaan, gaya hidup, kepribadian, motivasi dan sikap.
\end{abstract}

Kata Kunci: keputusan membeli, kelompok referensi, persepsi kualitas 


\section{PENDAHULUAN}

Keinginan tampil cantik mendorong wanita merias tubuh dan wajahnya. Menurut Jablonski (2006), aktivitas merias tubuh dan wajah ini telah sangat lama dilakukan oleh manusia bahkan sebelum manusia menutupi tubuh dengan pakaian yakni sekitar 75.000 tahun yang lalu. Aktivitas merias ini dilakukan secara meluas dan terus-menerus dan menjadi bagian dari pendefinisian diri sebagai individu dan sebagai manusia (Russel, 2010). Aktivitas merias semakin berkembang dari masa ke masa hingga terciptalah produk kecantikan seperti kosmetik (Jablonski, 2006).

Kosmetik merupakan alat yang terbilang praktis dalam aktivitas merias tubuh dan wajah. Kosmetik menurut Peraturan BPOM Nomor 27 Tahun 2013, adalah paduan bahan yang dimaksudkan untuk digunakan pada bagian luar tubuh manusia (kulit, rambut, kuku, bibir dan organ genital bagian luar) atau gigi dan membran mukosa mulut terutama untuk membersihkan, mewangikan, mengubah penampilan dan memperbaiki bau badan, melindungi, dan memelihara tubuh dalam kondisi baik (Perkosmi, 2013). Kosmetik berfungsi melindungi atau memperbaiki tubuh supaya tetap keadaan baik, bukan dimaksudkan untuk mengobati atau menyembuhkan suatu penyakit tertentu (Kusumawati \& Herlena, 2014).

Pria dan wanita memiliki kebutuhan yang berbeda di bidang kecantikan dan penggunaan produk kecantikan berdasarkan biaya tambahan dan jumlah produk yang digunakan. Berdasarkan dari segi biaya tambahan yang dikeluarkan, wanita membayar biaya tambahan sebesar US\$ 151 miliar per tahun untuk produk kecantikan, sedangkan pria tidak melakukan pembayaran tambahan (Adams, 2016). Berdasarkan penggunaan produk kecantikan, survey yang dilakukan oleh YouGov pada 1.000 orang dewasa di Amerika Serikat menemukan bahwa 35\% wanita menggunakan satu atau dua produk kecantikan sehari-hari, $17 \%$ wanita menggunakan tiga atau empat produk, bahkan $7 \%$ wanita menggunakan hingga enam produk dalam sehari. Sementara mayoritas laki-laki (54\%) tidak menggunakan satu pun produk kecantikan ketika bersiap-siap di pagi hari (Adams, 2016).

Besarnya kebutuhan akan produk kecantikan menyebabkan industri kosmetik tumbuh subur. Indonesia menjadi pemasok produk kosmetik keenam di dunia setelah Thailand, China, Singapura, Amerika Serikat, dan Prancis (Deny, 2015). Berdasarkan data lembaga riset pemasaran yang dikutip oleh Wulandari (2015), industri kosmetik Indonesia telah mencapai lebih dari US\$ 5 miliar dengan pertumbuhan rata-rata $12 \%$. Namun, transaksi produk halal termasuk kosmetik halal Indonesia hanya meraih US\$ 2 juta pada pameran ke-11 Malaysia International Halal Showchase (MIHAS) yang berlangsung di tahun 2014 (Mulyati, 2014). Dengan demikian, transaksi produk kosmetik halal Indonesia lebih sedikit dari transaksi kosmetik tanpa label halal. Hal ini ditandai dengan minimnya perusahaan yang melakukan sertifikasi halal.

Jumlah perusahaan kosmetik Indonesia yang melakukan sertifikasi halal masih sedikit (Rostanti \& Murdaningsih, 2016). Berdasarkan data yang dikutip oleh Rostanti dan Murdaningsih (2016), dari 500 perusahaan anggota Persatuan Perusahaan Kosmetika Indonesia (Perkosmi), hanya sekitar 70 perusahaan yang 
bersertifikasi halal. Jumlah perusahaan kosmetik berdasarkan data yang dikutip oleh Rostanti dan Murdaningsih (2016) ialah sebanyak 760 perusahaan. Padahal, Indonesia merupakan salah satu negara dengan jumlah populasi konsumen muslim yang tinggi yakni $13 \%$ dari total populasi muslim dunia (Pew Research Center, 2010). Jumlah populasi muslim dunia saat ini mencapai 2 miliar atau $23 \%$ dari seluruh penduduk dunia (Mulyati, 2014).

Tingginya populasi konsumen muslim khususnya di Tangerang Selatan yang mencapai $89,20 \%$ dari jumlah total warga (Badan Pusat Statistik, 2013), menjadikan kebutuhan produk yang sesuai Syariat atau halal adalah hal yang penting. Produk makanan dan minuman telah mendapat perhatian utama dalam proses memilih berdasarkan ketentuan Syariat. Namun, produk kosmetik halal belum menjadi prioritas yang dianggap penting dalam memilih dan memutuskan untuk dibeli. Hal ini ditandai dengan masih terbatasnya jumlah kosmetik halal yang ada di Indonesia, bila dibandingkan dengan populasi dan varian kosmetik.

Jumlah kosmetik yang mencantumkan label halal yang ada di Indonesia, masih terbatas. Sebagaimana data Badan Pengawas Obat dan Makanan (BPOM) yang dikutip oleh Kertopati dan Rustam (2015) menyatakan bahwa dari 1.550 total kosmetik, namun hanya sebanyak 21 produk yang berlabel halal, yakni sebesar $1,79 \%$ dari jumlah produk yang terdaftar. Data lainnya menyebutkan bahwa pada periode tahun 2010-2015 terdapat 907 produk atau 4\% dari total produk bersertifikasi halal MUI (LPPOM-MUI, 2015). Beberapa produsen belum mencantumkan label halal pada produknya sehingga besar kemungkinan perusahaan menggunakan bahan yang masih tergolong syubhat (diragukan kehalalannya) atau mungkin masih tergolong haram. Jumlah kosmetik yang memiliki sertifikasi halal, kemungkinan maksimal hanya 10\% dari seluruh kosmetik yang beredar di pasaran (Kusumawati \& Herlena, 2014).

Konsumsi produk kosmetik tanpa label halal pada konsumen muslim banyak terjadi berdasarkan data yang telah dikemukakan oleh Kusumawati dan Herlena (2014), Kertopati dan Rustam (2015), serta LPPOM-MUI (2015). Bagi konsumen muslim, produk yang belum bersertifikasi atau berlabel halal dinilai masih syubhat atau ada keraguan. Keraguan ada antara bahan yang dipakai atau proses yang dilakukan. Dalam hukum Islam, diterangkan bahwa haram hukumnya produk yang mengandung daging, minyak, dan lemak yang berasal dari babi atau binatang lain yang diharamkan dalam Islam. Oleh sebab itu, kehalalan produk menjadi hal yang penting untuk diperhatikan konsumen muslim dalam proses mengambil keputusan membeli suatu produk (Kusumawati\&Herlena, 2014).

Saat ini dalam penggunaan produk kosmetik, konsumen terutama yang berasal dari kalangan konsumen muslim perlu lebih berhati-hati terhadap keamanan dan kehalalan bahan baku produk kosmetik. Hal ini dikarenakan terdapat sejumlah bahan yang dijadikan bahan dasar pembuatan kosmetik yang diragukan kehalalannya. Menurut Direktur Lembaga Pengkajian Pangan, Obatobatan dan Kosmetika-Majelis Ulama Indonesia (LPPOM-MUI) ingredient produk kosmetik yang paling banyak digunakan dan beredar di pasar Indonesia saat ini seperti kolagen, gliserin, gelatin, ekstrak plasenta, cairan amnion, serta sodium heparin yang berasal dari bahan haram yang bertentangan dengan Syariat Islam. 
Lipstik merupakan salah satu kosmetik dekoratif yang dioleskan di atas permukaan kulit bibir dan rentan tertelan kemudian masuk aliran darah, sehingga perlu diperhatikan kehalalannya. Sebuah studi pada 360 partisipan pengguna lipstik berusia 19 sampai 65 tahun, rata-rata wanita menelan lipstik sebanyak 24 mg per hari, dan maksimum $80 \mathrm{mg}$ per hari (Bell, 2013). Konsumen wanita muslim perlu waspada karena beberapa produk lipstik dicurigai mengandung lemak babi (Evidia \& Hapsari, 2013). Oleh karena itu, keputusan membeli produk kosmetik terutama kosmetik dekoratif bibir perlu memperhatikan kehalalan produknya.

Menurut Evidia dan Hapsari (2013), titik kritis kehalalan dari kosmetik dekoratif bibir yakni bahan dasar yang terbuat dari lemak dan turunannya (gliserin, stearic, dan acid). Gliserin merupakan turunan lemak yang banyak terkandung pada bahan kosmetik yang dapat menimbulkan bahaya bagi kesehatan tubuh. Gliserin yang berasal dari hewanseperti gliserin babi, dapat mengganggu jaringan saraf, masalah pada Alat reproduksi dan mengganggu perkembangan tubuh (Mukharliza, 2013).

Selain gliserin, menurut Halal-MUI (2016) gelatin banyak digunakan dalam berbagai industri seperti kosmetik yang berfungsi sebagai penebal, pelekat, pembuih, penahan kelembaban, pembaik tekstur, pengikat, dan lain-lain. Lazimnya, gelatin dibuat dari tulang maupun kulit hewan ternak seperti sapi, kerbau, kambing, ikan, juga babi. Di luar negeri, terutama negara Eropa dan China, gelatin banyak dibuat dari tulang dan kulit babi. Dikarenakan proses pembuatannya yang mudah dan ketersediaan bahan baku yang berlimpah, sehingga harganya pun jauh lebih murah dibandingkan gelatin hewan lain. Hal ini sering menimbulkan kontroversi di Indonesia yang mayoritas penduduknya beragama Islam, apalagi hampir semua kebutuhan gelatin Indonesia diimpor dari luar negeri.

Kesulitan konsumen dalam membeli produk kecantikan ialah tidak mampu mengidentifikasi apakah produk yang dibeli mengandung bahan yang diharamkan atau tidak, baik bagi kesehatan atau tidak, dan tidak mengetahui istilah- istilah komposisi yang dicantumkan di tiap produk kecantikan (Mukharliza, 2013). Pengetahuan dan metode yang akurat diperlukan untuk mengetahui sumber bahan pembuatan produk kosmetik, apakah dari hewan yang halal, atau dari hewan yang diharamkan seperti babi (Halal-MUI, 2016). Upaya yang dilakukan adalah dengan melakukan analisis laboratorium karena secara kasat mata, tidak bisa dilihat apakah lemak di lipstik berasal dari hewani atau nabati. Oleh karenanya, lebih aman untuk memilih lipstik yang berlabel halal karena sudah melalui tahapan pengujian di LPPOM MUI (Evidia \& Hapsari, 2013).

Keputusan membeli adalah memilih satu dari dua atau lebih pilihan alternatif untuk dibeli (Shiffman, Kanuk, \& Hansen, 2012). Selain produk makanan dan minuman, kehalalan produk kosmetik yang dikonsumsi menjadi penting untuk diperhatikan para mahasiswi muslim. Hasil dari studi elisitasi yang penulis lakukan tanggal 17 dan 20 Oktober 2016 pada tujuh mahasiswi Fakultas Psikologi UIN Jakarta menyatakan bahwa empat dari tujuh responden membeli kosmetik dekoratif bibir tanpa label halal. Hal ini sejalan dengan studi elisitasi lainnya yang penulis lakukan tanggal 15 Desember 2015 melalui survey online 
menggambarkan bahwa 39\% atau 17 dari 44 mahasiswi Fakultas Psikologi UIN Jakarta tidak memerhatikan label halal dalam memilih kosmetik yang dibeli.

Beberapa faktor yang mempengaruhi keputusan membeli diantaranya adalah kelompok referensi dan persepsi kualitas produk. Studi terdahulu mengenai keputusan membeli menyatakan bahwa keputusan membeli produk atau merek dipengaruhi oleh kelompok referensi (Bearden \& Etzel, 1982). Penelitian lain yang dilakukan oleh Childers dan Rao (1992) serta Makgosa dan Mohube (2007) meneliti hal yang sama yaitu pengaruh kelompok referensi teman sebaya terhadap keputusan membeli. Sedangkan pengaruh kelompok referensi sosial terhadap keputusan membeli diteliti oleh Reza dan Valeencha (2013) serta Mudondo (2014). Dengan semakin berkembangnya teknologi komputer dan internet membuat kita menyaksikan munculnya kelompok baru yaitu kelompok atau masyarakat virtual, seperti beauty blogger.

Beauty blogger merupakan salah satu tipe kelompok referensi yakni kelompok masyarakat virtual. Schiffman, Kanuk dan Hansen (2012) menjelaskan bahwa kelompok atau masyarakat virtual merupakan salah satu dari lima kelompok referensi spesifik yang mempengaruhi sikap dan perilaku konsumen dalam membeli. Komunitas virtual memberikan kesempatan bagi pemasar untuk mengatasi kepentingan konsumen secara umum, yang menjadi salah satu kenikmatan utama bagi konsumen, dan juga untuk meningkatkan pengalaman konsumsi melalui diskusi (Shiffman, Kanuk, \& Hansen, 2012).

Kelompo kreferensi beauty blogger dipilih berdasarkan kekurangan penelitian terdahulu yang dilakukan oleh Bearden dan Etzel(1982) mengenai kelompok referensi. Selain itu, berdasarkan studi pendahuluan penulis tanggal 20 April 2016 pada 22 mahasiswi Fakultas Psikologi UIN menggambarkan bahwa 60\% (13 dari

22) responden menjadikan kelompok di social media atau website sebagai referensi responden. Diperkuat dengan studi pendahuluan lain yang penulis lakukan tanggal 17 dan 20 Oktober 2016, enam dari tujuh responden menjawab beauty blogger sebagai kelompok referensi responden.

Selain kelompok referensi, persepsi kualitas produk merupakan salah satu faktor yang mempengaruhi keputusan membeli. Studi terdahulu yang dilakukan oleh Yee dan San (2011), serta Harjati dan Sabu (2014) menunjukkan bahwa persepsi kualitas memiliki pengaruh terhadap keputusan membeli pada konsumen. Sejalan dengan studi terdahulu, studi pendahulu yang dilakukan penulis tanggal 15 Desember 2015 melalui survey kepada 44 mahasiswi Fakultas Psikologi UIN Jakarta menemukan bahwa $70 \%$ atau 31 dari 44 responden menjawab kualitas produk sebagai bahan pertimbangan utama dalam memilih kosmetik yang dibeli.

\section{KAJIAN TEORI}

\section{Keputusan Membeli}

Keputusan membeli pada penelitian ini mengacu pada pendapat Schiffman, Kanuk dan Hansen (2012) yakni pemilihan suatu tindakan dari dua atau lebih pilihan alternatif yang diambil konsumen,

Dalam hal ini membuat keputusan membeli kosmetik dekoratif bibir tanpa label halal. Definisi dari Schiffman, Kanuk dan Hansen (2012) dipilih karena 
keputusan membeli dalam penelitian ini tidak hanya terbatas pada merek spesifik dan bukan suatu kecenderungan untuk membeli, melainkan individu memutuskan untuk melakukan keputusan membeli atau tidak membeli produk kosmetik dekoratif bibir tanpa label halal.

\section{Kelompok Referensi}

Berdasarkan beberapa teori diatas, kelompok referensi pada penelitian ini mengacu pada konsep yang dikembangkan oleh Park dan Lessig (1977) yang menjelaskan kelompok referensi sebagai sebuah tindakan atau imajinasi individu atau kelompok yang diyakini memiliki relevansi yang signifikan terhadap evaluasi individu, aspirasi atau perilaku. Definisi dari Park dan Lessig (1977) dipilih karena merupakan teori besar mengenai kelompok referensi yang telah didukung dan diteliti oleh beberapa penulis terdahulu yaitu Bearden dan Etzel (1982), Childers dan Rao (1992), serta Makgosa dan Mohube (2007).

\section{Persepsi Kualitas}

Pada penelitian ini, persepsi kualitas mengacu pada pendapat Durianto, Sugiarto dan Budiman (2004) yang mendefinisikan "Persepsi kualitas merupakan persepsi konsumen terhadap keseluruhan kualitas atau keunggulan suatu produk yang sama dengan maksud yang diharapkannya". Persepsi kualitas adalah salah satu kunci dimensi ekuitas merek. Persepsi kualitas mempunyai atribut penting yang dapat diaplikasikan dalam berbagai hal seperti kualitas aktual atau objektif, kualitas isi produk dan kualitas proses manufaktur. Definisi dari Durianto, Sugiarto dan Budiman (2004) dipilih karena persepsi kualitas tidak bisa ditetapkan secara objektif karena persepsi kualitas melibatkan apa yang penting bagi seorang konsumen.

\section{METODE PENELITIAN}

\section{Populasi, sampel dan teknik pengambilan sampel}

Populasi dalam penelitian ini yaitu mahasiswi aktif Fakultas Psikologi UIN Jakarta yang berjumlah 584 orang dengan karakteristik membeli kosmetik dekoratif bibir seperti lip stick, lip gloss, lip balm, lip tint, atau lip cream. Ada pun jumlah sampel dalam penelitian ini adalah 255 responden mahasiswi aktif di Fakultas Psikologi UIN Jakarta. Metode pengambilan sampel pada penelitian ini bersifat non probability sampling dimana teknik sampling ini tidak memberikan peluang yang sama bagi setiap anggota populasi untuk dijadikan sampel. Teknik sampling yang digunakan adalah convenience sampling dengan karakteristik mahasiswi aktif Fakultas Psikologi UIN Jakarta yang membeli kosmetik dekoratif bibir.

\section{Instrumen penelitian}

Terdapat tiga alat ukur yang digunakan dalam penelitian ini, yaitu:

1. Skala Keputusan Membeli

Pada skala keputusan membeli, penulis membuat pernyataan yang akan membedakan respon konsumen dalam membuat keputusan membeli atau tidak membeli kosmetik dekoratif bibir tanpa label halal. Apabila responden menjawab tidak masalah membeli kosmetik dekoratif bibir tanpa label halal, 
maka dikategorikan membeli kosmetik dekoratif bibir tanpa label halal dengan nilai skor 1 . Sedangkan, apabila responden menjawab harus ada label halal untuk membeli kosmetik dekoratif bibir, maka dikategorikan tidak membeli kosmetik dekoratif bibir tanpa label halal dengan nilai skor 0 .

2. Skala Kelompok Referensi

Kelompok referensi pada penelitian ini dibedakan menjadi dua alat ukur. Pertama, alat ukur kelompok referensi beauty blogger dimana respon dikategorikan menjadi memilih dengan nilai skor 1 atau tidak memilih beauty blogger sebagai kelompok referensi dengan nilai skor 0 .

Kedua, alat ukur dengan menggunakan model skala Likert yang mengukur tingkat pengaruh kelompok referensi berdasarkan teori yang dikemukakan oleh Park \& Lessig (1977) yang telah diadaptasi dan dimodifikasi. Subjek diminta untuk memilih salah satu kategori dari empat kategori jawaban yang mewakili dirinya yaitu 4 "Sangat Sesuai" (SS), 3 "Sesuai" (S), 2 "Tidak Sesuai" (TS), dan 1 "Sangat Tidak Sesuai" (STS).

1. Skala Persepsi Kualitas

Skala persepsi kualitas produk yang didasarkan pada hasil elisitasi dan teori yang dikemukakan oleh Garvin (Durianto, Sugiarto \& Budiman, 2004). Subjek diminta untuk memilih salah satu kategori dari empat kategori jawaban yang mewakili pendapat dirinya yaitu 4 "Sangat Setuju" (SS), 3 "Setuju" (S), 2 "Tidak Setuju" (TS), dan 1 "Sangat Tidak Setuju" (STS).

\section{HASIL PENELITIAN}

\section{Besaran Muatan Independent Variable terhadap Dependent Variable}

Hasil uji hipotesis pada penelitian ini menggunakan regresi logistik dapat dilihat pada tabel

Tabel 1

Uji Hipotesis

\begin{tabular}{rrrr}
\hline Step & Chi-square & Df & Sig. \\
\hline 1 & 4,403 & 8 & .819 \\
\hline
\end{tabular}

Tabel 1 menunjukkan bahwa nilai chi- square sebesar 4,403 dengan $\mathrm{p}=0.819$ $(>0.05)$ artinya model teori yang digunakan dalam penelitian ini fit dengan data. Dengan demikian, ada pengaruh dari kelompok referensi dan persepsi kualitas produk terhadap keputusan membeli kosmetik dekoratif bibir tanpa label halal. Setelah pengujian model fit, penulis melihat besaran $R$ square untuk mengetahui berapa persen varians variabel dependen yang dijelaskan oleh seluruh variabel independen. Berikut dipaparkan besar $r$ square pada tabel 1.2.

\section{Tabel 2}

$R$ Square

\begin{tabular}{ccc}
\hline Step & Cox dan Snell R Square & Nagelkerke R Square \\
\hline 1 & .231 & .308 \\
\hline
\end{tabular}


Dari tabel 2 dapat dilihat nilai Nagelkerke $R$ square penelitian ini sebesar 0.308 atau $30,8 \%$. Artinya, proporsi varians logit keputusan membeli yang dijelaskan oleh seluruh variabel independen yaitu beauty blogger, informational influence,utilitarian influence, value-expressive influence, performance, serviceability, reliability, feature, durability,conformance, fit and finish adalah sebesar 30,8\%, sedangkan 60,2\%, dipengaruhi oleh variabel independen lain di luar penelitian ini.

Tahap selanjutnya adalah melihat besaran koefisien dan tingkat signifikansi masing-masing variabel independen. Untuk mengetahui signifikan atau tidaknya koefisien regresi yang dihasilkan, penulis melihat nilai signifikansi pada tabel 1.3 di kolom kelima dari kiri. Jika sig< 0,05 , maka koefisien regresi yang dihasilkan signifikan pengaruhnya terhadap keputusan membeli kosmetik dekoratif bibir tanpa label halal.

Pada tabel 3 dapat dilihat bahwa terdapat tiga variabel yang signifikan memengaruhi keputusan membeli kosmetik dekoratif bibir tanpa label halal, yaitu beauty blogger, performance, dan serviceability. Variabel lainnya yaitu informational influence, utilitarian influence, value-expressive influence, reliability, feature, durability, conformance, fit and finish tidak signifikan memengaruhi keputusan membeli kosmetik dekoratif bibir tanpa label halal.Penafsiran dalam analisis regresi logistik dilakukan melalui empat tahap, yaitu logit, odds, odds ratio, dan probabilitas. Logit atau log odds merupakan log dari rasio dua probabilitas.

Odds adalah rasio dari dua probabilitas, sedangkan odds ratio adalah rasio dari dua odds. Odds ratio dapat dijelaskan dalam bentuk persen perubahan odds ratio (percent change), yaitu nilai perubahan pada odds ratio dalam persen jika variabelnya kontinum. Probabilitas adalah besarnya peluang terjadinya perilaku.

Berdasarkan hasil uji hipotesis penelitian, diketahui terdapat tiga variabel independen yang mempengaruhi variabel dependen secara signifikan seperti yang ditampilkan pada tabel 3 .

\section{Tabel 3}

Koefisien Regresi Logistik

\begin{tabular}{|c|c|c|c|c|c|}
\hline \multicolumn{2}{|c|}{ B } & S.E & $\mathrm{df}$ & Sig. & $\operatorname{Exp}(B)$ \\
\hline Beautyb & 1,153 & 0,340 & 1 & 0,001 & 3,168 \\
\hline Info & $-0,023$ & 0,019 & 1 & 0,232 & 0,978 \\
\hline Utili & $-0,001$ & 0,019 & 1 & 0,973 & 0,999 \\
\hline Val-expr & $-0,017$ & 0,018 & 1 & 0,344 & 0,983 \\
\hline Perform & 0,065 & 0,030 & 1 & 0,033 & 1,067 \\
\hline Service & $-0,043$ & 0,020 & 1 & 0,032 & 0,958 \\
\hline Reliable & 0,028 & 0,030 & 1 & 0,358 & 1,028 \\
\hline Feature & $-0,005$ & 0,032 & 1 & 0,877 & 0,995 \\
\hline Durable & $-0,009$ & 0,026 & 1 & 0,733 & 0,991 \\
\hline Conform & 0,013 & 0,031 & 1 & 0,669 & 1,013 \\
\hline Fit finish & 0,045 & 0,028 & 1 & 0,108 & 1,046 \\
\hline Constant & $-3,167$ & 1,593 & 1 & 0,047 & 0,042 \\
\hline
\end{tabular}




\section{Proporsi varian}

\section{Tabel 4}

Proporsi Varians Masing-masing Variabel Independen

\begin{tabular}{lc}
\hline \multicolumn{1}{c}{ Variabel Independen } & $\boldsymbol{R}$ Square changes \\
\hline Beauty blogger & 0,103 \\
Informational infl & 0,008 \\
Utilitarian infl & 0,001 \\
Value-expr infl & 0 \\
Performance & 0,162 \\
Serviceability & 0,012 \\
Reliability & 0,007 \\
Feature & 0,001 \\
Durability & 0 \\
Conformance & 0,003 \\
Fit and finish & 0,011 \\
Total & 0,308 \\
\hline
\end{tabular}

Pada bahasan sebelumnya diketahui terdapat tiga variabel independen yang mempengaruhi variabel dependen secara signifikan yaitu, performance, beauty blogger dan serviceability. Pada bahasan kali ini, penulis ingin memberikan gambaran mengenai sumbangan masing- masing variabel bebas terhadap variabel terikat (lihat tabel 4).Dalam tabel 4, diketahui bahwa variabel performance merupakan variabel bebas yang memberikan sumbangan terbesar terhadap keputusan membeli kosmetik dekoratif bibir tanpa label halal, disusul dengan beauty blogger dan serviceability.

\section{KESIMPULAN DAN SARAN}

\section{Kesimpulan}

Berdasarkan hasil analisis data penelitian, kesimpulan yang dapat diambil ialah hipotesis keseluruhan dari penelitian ini yang menyatakan bahwa terdapat pengaruh kelompok referensi dan persepsi kualitas produk terhadap keputusan membeli kosmetik dekoratif bibir tanpa label halal, tidak ditolak. Berdasarkan hasil uji hipotesis yang telah dilakukan terdapat tiga variabel independen yang mempengaruhi keputusan membeli secara signifikan yaitu performance, beauty blogger, dan serviceability. Prediktor yang mempengaruhi keputusan membeli dengan nilai terbesar merupakan performance.

\section{Diskusi}

Pada penelitian ini, terbukti bahwa variabel kelompok referensi dan persepsi kualitas produk berpengaruh signifikan pada keputusan membeli kosmetik dekoratif bibir tanpa label halal. Pada penelitian ini tidak dibatasi jenis produk dan merek, sehingga variabel kelompok referensi dimensi informational influence, utilitarian influence, dan value-expressive influence tidak berpengaruh signifikan terhadap keputusan membeli. Pada penelitian ini, populasi penelitian yakni mahasiswi Muslim di Fakultas Psikologi UIN Jakarta. Penelitian ini 
membuktikan bahwa kelompok referensi beauty blogger memiliki pengaruh signifikan terhadap keputusan membeli kosmetik dekoratif bibir tanpa label halal pada mahasiswi Fakultas Psikologi UIN Jakarta. Pada penelitian ini terbukti bahwa kelompok referensi beauty blogger memberikan kontribusi yang signifikan pada keputusan membeli kosmetik dekoratif bibir tanpa label halal dan mayoritas beauty blogger tidak memperlihatkan label halal pada ulasannya. Pada penelitian ini terbukti bahwa beauty blogger, dan persepsi performance berkontribusi dan berpengaruh signifikan pada keputusan membeli kosmetik dekoratif bibir tanpa label halal. Pada penelitian ini terbukti bahwa kelompok referensi beauty blogger memberikan kontribusi yang signifikan pada keputusan membeli kosmetik dekoratif bibir tanpa label halal dan mayoritas beauty blogger tidak memperlihatkan label halal pada ulasannya.

\section{Saran}

Berdasarkan hasil penelitian, maka saran yang dapat diberikan adalah sebagai berikut:

1. Penulis menyarankan untuk penelitian selanjutnya menguji faktor lain yang dapat mempengaruhi keputusan membeli seperti kebudayaan, keluarga, peran dan status sosial,usia, pekerjaan, gaya hidup, kepribadian, motivasi, dan sikap.

2. Penulis menyarankan untuk penelitian selanjutnya dilakukan pengelompokan atau pembatasan jenis produk dan merek kosmetik dekoratif bibir tanpa label halal yang lebih spesifik dalam mengukur kelompok referensi.

3. Penulis menyarankan untuk penelitian selanjutnya dilakukan pada mahasisiwi muslim dengan domisili yang berbeda, misalnya pada mahasiswi muslim yang berkuliah di kawasan Jabodetabek, dan atau pada mahasiswi yang tinggal di pesantren atau asrama, karena sampel dari lokasi lain memiliki karakteristik yang berbeda-beda sehingga hasilnya pun dapat berbeda.

4. Penulis memiliki saran untuk para beauty blogger muslim atau mahasiswi muslim yang aktif sebagai beauty blogger, agar menambah wawasan dan ulasan mengenai kehalalan kosmetik dekoratif bibir yang ditulis di blog yang bertujuan untuk meningkatkan kesadaran halal dan membantu wanita muslim dalam mempertimbangkan keputusan membeli produk kosmetiknya.

5. Penulis memiliki saran untuk beauty blogger bahwa label halal pada kosmetik dekoratif bibir penting untuk diperlihatkan.

6. Penulis memiliki saran untuk LPPOM-MUI dan produsen keputusan membeli kosmetik dekoratif bibir tanpa label halal pada mahasiswi Fakultas Psikologi UIN Jakarta. Penulis memiliki saran untuk para beauty blogger muslim atau mahasiswi muslim yang aktif sebagai beauty blogger, agar menambah wawasan dan ulasan mengenai kehalalan kosmetik dekoratif bibir yang ditulis di blog yang bertujuan untuk meningkatkan kesadaran halal dan membantu wanita muslim dalam mempertimbangkan keputusan membeli produk kosmetiknya.

7. Penulis memiliki saran untuk beauty blogger bahwa label halal pada kosmetik dekoratif bibir penting untuk diperlihatkan.

8. Pada penelitian ini terbukti bahwa beauty blogger, dan persepsi performance 
berkontribusi dan berpengaruh signifikan pada keputusan membeli kosmetik dekoratif bibir tanpa label halal. Penulis memiliki saran untuk LPPOM-MUI dan produsen kosmetik halal untuk lebih aktif memberikan program penyuluhan melalui media sosial bekerja sama dengan beauty blogger yang bertujuan untuk membantu masyarakat mengenali pentingnya menggunakan produk kosmetik halal yang baik bagi kesehatan dan nyaman digunakan.

9. Pada penelitian ini terbukti bahwa persepsi kualitas produk berupa performance dan serviceability berkontribusi dan berpengaruh signifikan pada keputusan membeli kosmetik dekoratif bibir tanpa label halal. Penulis memiliki saran untuk produsen kosmetik dekoratif bibir berlabel halal untuk lebih aktif membangun persepsi performance produk yang lebih positif dengan mengiklankannya di berbagai media, dan membangun persepsi pelayanan (serviceability) produk dengan melibatkan internet dan media elektronik seperti blog atau website untuk lebih memudahkan konsumen berinteraksi bila mengalami keluhan mengenai produk atau pun mengenai tutorial pemakaian produk yang benar yang ditampilkan di halaman website.

\section{DAFTAR PUSTAKA}

Adams, R. (2016). This is why it's more expensive to be a woman. Diunduh tanggal 27 Desember 2016 dari http://www.huffingtonpost.com

Badan Pusat Statistik. (2013). Tangerang Selatan Dalam Angka. Kota Tangerang Selatan

Bearden, W. O., \& Etzel, M. J. (1982). Reference group influence on product and brand purchase decision. Journal of consumer research, 9, 183-194.

Bell, N. (2013). Beauty myth busting: do women actually eat 7 pounds of lipstick in their lifetimes. Diunduh pada 28 November 2015 dari http://www.futurederm.com

Childers, T.L., \& Rao, A. R. (1992). The influence of familial and peer based reference groups on consumer decision. Journal of consumer research, 19, 198-211.

Deny, S. (2015). Malaysia jadi pasar produk kosmetik RI. Diunduh pada 27 Desember 2016 dari http://bisnis.liputan6.com.

Dianti, M. R. (2013). Pengaruh faktor psikologis dan subbudaya agama terhadap keputusan pembelian produk halal di kota padang (studi kasus pada kosmetik wardah). Jurnal Manajemen, 2(1), 1-10.

Durianto, D., Sugiarto, Budiman, L. K. (2004). Brand equity ten strategi memimpin pasar. Jakarta: Gramedia Pusaka Utama.

Evidia, S., \& Hapsari, E. (2013). Waspadai lipstik berbahan babi ini solusinya. Diunduh tanggal 2 november 2016 dari http://www.republika.co.id

Halal-MUI. (2016). Workshop Internasional Metode Analisa Kehalalan Gelatin. Diunduh pada 2 November 2016 dari http://www.halalmui.org Harjati,

L., \& Sabu, L. O. (2014). Pengaruh persepsi kualitas produk terhadap keputusan pembelian the body shop. E-journal Widya Ekonomika, 1, 2530 .

Hawkins, I. D., Mothersbough, L. D., Best, J. R. (2007). Consumer behavior: building marketting strategy, 10th. Edd. New York: McGraw Hill. 
Herditya, W. A. (2013). Pengaruh persepsi kualitas produk pelembab wajah x terhadap loyalitas konsumen pada mahasiswi uin jakarta. Skripsi. Fakultas Psikologi UIN Syarif Hidayatullah.

Jablonski, N. G. (2006). Skin: a natural history. Berkeley: University of California Press.

Kazmi, S. Q. (2012). Consumer perception and buying decisions the pasta study. International journal of advancements in research \& technology, 1, 1-10.

Kertopati, L., \& Rustam, D.A. (2015). BPOM: Kosmetik halal semakin diminati. Diunduh tanggal 5 Desember 2015 dari http://life.viva.co.id

Kotler, P., \& Armstrong, G. (2011). Principles of marketing 14th edition. New Jersey: Pearson Prentice Hall.

Kusumawati, Y., \& Herlena, B. (2014). Hubungan antara persepsi terhadap kelompok referensi dengan pengambilan keputusan membeli produk kosmetik tanpa label halal pada mahasiswa muslim, Jurnal Psikologi Integratif, 1, 100-109.

LPPOM-MUI. (2015). Statistik sertifikasi halal Indonesia. Diunduh tanggal 26 Mei 2016 dari http://halalmui.org

Makgosa, R., \& Mohube, K. (2007). Peer influence on young adult's products purchase decisions. African journal of business management, 1, 64-71.

Mowen, J. C., Minor, M. (2001). Consumer behavior, 5th ed. New Jersey: Harcourt College Publisher.

Mudondo, C. D. (2014). The social context of consumption: analysing social reference group factors that influence millennial mobile phone purchasing behavior. International journal of management sciences, 3, 140-146.

Mukharliza, A. (2013). Kandungan kosmetik yang bahayakan kulit.

Diunduh tanggal 1 September 2016 dari http://www.lifestyle.okezone.com Mulyati, A. (2014). Produk halal Indonesia raih transaksi usd 2 juta di mihas 2014. Diunduh tanggal 26 Mei 2016 dari http://www.kemendag.go.id

Pampel, F. C. (2000). Logistic regression: a primer. New York: Sage Publication

Park, C. W., \& Lessig, V. P. (1977). Students and house wives: differences in susceptibility to reference group influence. Journal of Consumer Research, 1, 102-110.

Pew Research Center. (2010). Muslim population of Indonesia. Diunduh tanggal 3 desember 2016 dari http://www.pewforum.org.

Perkosmi. (2013). Peraturan BPOM Nomor

27 Tahun 2013: Pengawasan Pemasukan Obat Dan Makanan Ke Dalam Wilayah Indonesia. Diunduh tanggal 3 desember 2015 dari http://www.perkosmi.com

Peter, J. P., \& Olson, J. (2009). Consumer behavior \& marketing strategy, ninth edition. New York: McGraw- Hill.

Plaza, B. (2014). Analisis Pengaruh persepsi kualitas, citra merek, lokasi dan kualitas pelayanan terhadap keputusan pembelian produk kfc. Skripsi. Fakultas Ekonomi dan Bisnis UIN Syarif Hidayatullah.

Revani, M. (2014). Pengaruh persepsi kualitas produk dan brand image terhadap loyalitas konsumen. Skripsi. Fakultas Psikologi UIN Syarif Hidayatullah. 
Reza, S. A., \& Valeencha, S. (2013). Influence of social reference groups on automobile buying decision- research on young executives. World Review of Business Research, 1, 197-210.

Rostanti, Q., Murdaningsih, D. (2016). Perusahaan kosmetik yang bersertifikasi halal masih minim. Diunduh pada 3 Desember 2016 dari http://republika.co.id.

Russel, R. (2010). Why cosmetics work. Dalam R.B. Adams, N, Ambidi, K. Nakayama, \& S. Shimojo, The science of vision (hal. 186). New York: Oxford University Press.

Schiffman, L. G., Kanuk, L. L., \& Hansen, H. (2012). Consumer behavior a european outlook second edition. New Jersey: Pearson.

Setiadi, J. N. (2003). Perilaku konsumen. Jakarta: Prenada Media.

Simamora, B. (2004). Panduan riset perilaku konsumen. Jakarta: PT Gramedia Pustaka Utama.

Solomon, M., Bamossy, G., Askegaard, S., \& Hogg, M. K. (2013). Consumer behaviour a european perspective. Harlow: Pearson Education.

Suelin, C. (2010). Understanding consumer purchase behaviour in the japanese personal grooming sector. Journal of Yasar University, 9, 2821-2831.

Tranggono, R. I., \& Latifah, F. (2007). Buku pegangan ilmu pengetahuan kosmetik. Jakarta: Gramedia Pustaka Utama.

Thompson, B. (2004). Exploratory and Factor Analysis. Washington DC. American Psychological Association.

Umar, H. (2000). Riset pemasaran dan perilaku konsumen. Jakarta: PT Gramedia Pustaka Utama.

Widhiarso, W. (2010). Jumlah sampel dalam pemodelan persamaan struktural. Diunduh pada 28 November 2015 dari http://widhiarso.staff.ugm.ac.id

Wulandari, S. (2015). Kosmetik tak ada matinya. Diunduh tanggal 3 Desember 2015 dari http://www.majalahreviewweekly.c om

Yee, C. J., \& San, N. G. (2011). Consumers perceived quality, perceived value and perceived risk towards purchase decision on automobile. American Journal of Economics and Business Administration, 3 (1) 7-57. 